\title{
Mating system and gene flow in the red seaweed Gracilaria gracilis: effect of haploid-diploid life history and intertidal rocky shore landscape on fine- scale genetic structure
}

\author{
CR Engel ${ }^{1}, \mathrm{C}$ Destombe $^{1}$ and $\mathrm{M}$ Valero $^{1}$ \\ Laboratoire de Génétique et Evolution des Populations Végétales, CNRS UPRESA 8016, Bât. SN2, Université de Lille I, Villeneuve \\ d'Ascq 59655, France
}

\begin{abstract}
The impact of haploid-diploidy and the intertidal landscape on a fine-scale genetic structure was explored in a red seaweed Gracilaria gracilis. The pattern of genetic structure was compared in haploid and diploid stages at a microgeographic scale $(<5 \mathrm{~km})$ : a total of 280 haploid and 296 diploid individuals located in six discrete, scattered rock pools were genotyped using seven microsatellite loci. Contrary to the theoretical expectation of predominantly endogamous mating systems in haploid-diploid organisms, G. gracilis showed a clearly allogamous mating system. Although withinpopulation allele frequencies were similar between haploids and diploids, genetic differentiation among haploids was more than twice that of diploids, suggesting that there may be a lag between migration and (local) breeding due to the long generation times in $G$. gracilis. Weak, but significant,
\end{abstract}

population differentiation was detected in both haploids and diploids and varied with landscape features, and not with geographic distance. Using an assignment test, we establish that effective migration rates varied according to height on the shore. In this intertidal species, biased spore dispersal may occur during the transport of spores and gametes at low tide when small streams flow from high- to lower-shore pools. The longevity of both haploid and diploid free-living stages and the long generation times typical of $G$. gracilis populations may promote the observed pattern of high genetic diversity within populations relative to that among populations.

Heredity (2004) 92, 289-298, advance online publication, 17 December 2003; doi:10.1038/sj.hdy.6800407

Keywords: assignment test; haploid-diploid life cycle; microsatellites; patchy distribution; polyembryony

\section{Introduction}

The spatial structure of genetic diversity plays an important role when estimating biodiversity below the species level and when examining the interaction of a species with environmental factors that affect the ecosystem. Factors that govern dispersal between populations and genetic structure within populations may be intrinsic (eg life cycle, mating system) or extrinsic (eg landscape of habitat, medium of transport). While numerous studies have focused on the correlation between life history traits and spatial genetic differentiation among and within populations (see for a review, in plants, Brown et al, 1990; Hamrick and Godt, 1997; and in marine invertebrates, Palumbi, 1994; Bohonak, 1999; Féral, 2001), comparatively few studies have explored local genetic differentiation in relation with fine-scale variation in landscape characteristics (see, for review, Sork et al, 1999). Rare in groups other than plants or animals, explorations of the links between life history

Correspondence: $M$ Valero, Laboratoire de Génétique et Evolution des Populations Végétales, CNRS UPRESA 8016, Bât. SN2, Université de Lille I, Villeneuve d'Ascq 59655, France. E-mail: valero@sb-roscoff.fr ${ }^{1}$ Current address: Evolution et Génétique des Populations Marines (EGPM), UMR CNRS-UPMC 7127, Station Biologique de Roscoff, BP 74, Place Georges Teissier, 29680 Roscoff Cedex, France.

Received 29 November 2002; accepted 10 September 2003 characteristics and/or landscape dynamics with the population genetic structure should be particularly interesting for a species such as the red seaweed Gracilaria gracilis.

G. gracilis has a complex haploid-diploid life cycle typical of red seaweeds, including two free-living stages of different ploidy levels - a diploid (tetrasporophyte) stage and a haploid (gametophyte) stage - and three dispersal units (haploid spores, diploid spores and male gametes). The alternation of haploid and diploid individuals in the life cycle implies that the recruitment of each stage depends on the survival, fertility and migration, as well as on the efficiency of selection, of the other stage. Second, sexual reproduction - with meiosis occurring in the diploid stage and fertilization in the haploid stage - and clonal multiplication - via the cystocarp (see Figure 1) - are both possible. Finally, G. gracilis individuals are found in rock pools that are formed at low tide in the intertidal zone exemplifying small-scale patchiness with concomitant ecophysiological variations in the landscape, possibly subject to different selection pressures.

In contrast to angiosperms where hermaphroditism is the most common breeding system (72\% of species; Richards, 1997), most red seaweed species are dioecious (Hawkes, 1990), that is, male and female sexual organs occur on different individuals. Thus, by constraint, most 


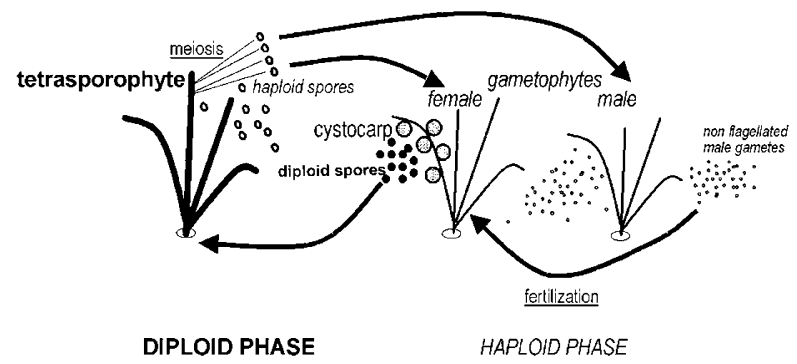

Figure 1 Haploid-diploid life cycle in G. gracilis. The cycle is described in the Material and methods section. Italic characters and thin lines, haploid phase stages; bold characters and thick lines, diploid phase stages; arrows, dispersal. The cystocarp is composed of a haploid maternal envelope and a diploid sporogenic tissue that gives rise to thousands of genetically identical diploid spores (carpospores).

Rhodophytes are obligatory outcrossers. However, in haploid-diploid species, mating between male and female gametophytes descending from the same parental (tetra)sporophytic individual is wholly analogous to selfing. Consequently, when both spore and gamete dispersal are restricted, the levels of inbreeding similar to those reported in hermaphroditic flowering plant species may be observed in dioecious haploid-diploid seaweed species. Indeed, mosses and ferns, also haploiddiploid organisms, of which some are capable of both inter- and intragametophytic selfing, show a range of inbreeding rates (Soltis et al, 1988; Innes, 1990; Shaw, 1991). Moreover, clonality (and the subsequent reduction in genotypic diversity) may occur in red algae, via the cystocarp, through a process similar to polyembryony. Polyembryony has been described in invertebrates (Craig et al, 1997) and in pine trees (eg Rogers et al, 1999) and corresponds to the splitting of one single biparental embryo into many genetically identical embryos that are different from their mother (Craig et al, 1997). Interestingly, in the context of inbreeding and clonality, theoretical models suggest that endogamous mating systems may be associated with life cycles characterized by a free-living prolonged haploid phase (Otto and Goldstein, 1992; Richerd et al, 1993b; Otto and Marks, 1996). In fact, the purging of deleterious mutations, exposed to selection in the haploid phase reduces the genetic load, buffering inbreeding depression and/or creating favorable genetic associations, either of which promote selfing, inbreeding or asexual reproduction (Otto and Goldstein, 1992; Richerd et al, 1993b; Otto and Marks, 1996).

Seaweeds are generally considered poor dispersers (see the special issue of the British Phycological Journal 1992, 27(3)), as spores and gametes are commonly short lived (Santelices, 1990). Indeed, in G. gracilis, shortdistance dispersal occurs via three dispersal stages (haploid spores, diploid spores and male gametes) of short duration (maximum lifespans range from $6 \mathrm{~h}$ to ca. 2-3 days). Taken together, the combined features of the haploid-diploid life history of G. gracilis may favor a fine-scale genetic structure through limited dispersal (due to short-lived spores and gametes) and/or through a reduction in local genotypic diversity (due to a polyembryony-like process). In addition, when compared to land plants or marine invertebrates where pollen/sperm and seeds/larvae are dispersed, haploid spores represent an additional dispersive element on microgeographic scales. This 'additional' dispersal stage may locally affect gene flow between populations, particularly if haploid and diploid spores have different dispersal properties. For example, in G. gracilis, experiments under controlled light conditions suggest that haploid spores have better dispersal capacities than diploid spores: haploid spores have better buoyancy and show higher survival rates (Destombe et al, 1992).

On the scale of a single shore $(1-5 \mathrm{~km})$, individuals of G. gracilis are confined to discrete, scattered rock pools in the intertidal zone. This heterogeneous and dynamic environment features dramatic differences in the ecophysiological and biotic environmental characteristics over small spatial scales (Ruckelshaus, 1998; Zuccarello, 2001). In particular, the duration and frequency of emersion increases with increasing height on the shore: high-shore positions experience longer periods of isolation along with large, daily fluctuations in temperature, salinity, light intensity, etc compared to the immersed, open, relatively buffered low-shore positions. The smallscale patchiness of this species habitat and the cyclic spatiotemporal isolation of high-shore populations suggest that microgeographic genetic differentiation, even within a single shore, is possible (Engel et al, 1997).

In this study, we analyzed the microgeographic population genetic structure in G. gracilis. Using seven polymorphic microsatellite loci, we evaluated the consequences of the haploid-diploid life history and intertidal rocky shore landscape on the genetic diversity and organization in this species. First, we analyzed the mating system and assessed the influence of a polyembryony-like process on genotypic diversity. Second, we compared the organization of the genetic diversity of both free-living haploid and diploid stages. Third, we investigated gene flow among populations (rock pools). Finally, we considered the population structure in light of the spatial positions of populations with respect to height on the shore.

\section{Materials and methods}

\section{Study species}

Populations of G. gracilis (Gracilariales, Rhodophyta) consist of isomorphic, perennial haploid male and female (gametophytic) and diploid (tetrasporophytic) individuals. Individuals are fixed to the substratum by a perennial holdfast bearing deciduous spaghetti-like thalli. As in all sexual life cycles, these haploid and diploid phases are interconnected through meiosis and syngamy (Figure 1). Meiosis occurs in diploid individuals, producing thousands of haploid spores (tetraspores). Haploid spores are dispersed and develop into new haploid individuals. Mitotic gametogenesis takes place in haploid individuals; male gametes are released into the water column and fertilization occurs on the female. The fertilized female gamete develops into a cystocarp, a macroscopic hemispherical fruiting body made up of maternal and zygotic tissues. The zygote multiplies by mitosis, producing thousands of genetically identical diploid spores (carpospores). Diploid spores are dispersed and new diploid individuals arise from these diploid spores. At the end of the reproductive 
season, thalli weaken and break off. Thus, long-distance dispersal may be ensured by floating torn thallus fragments that remain viable and continue to release spores or gametes.

\section{Study populations}

G. gracilis individuals occupy intertidal rock pools, where they remain immersed at ebb tide. Six rock pools were studied at two sites on the French coast of the Strait of Dover, Cape Gris-Nez $\left(50^{\circ} 53^{\prime} \mathrm{N}, 1^{\circ} 35^{\prime} \mathrm{E}\right)$ and, $5 \mathrm{~km}$ away, Audresselles $\left(50^{\circ} 49^{\prime} \mathrm{N}, 1^{\circ} 35^{\prime} \mathrm{E}\right)$ (Figure 2). Three rock pools situated at different tide levels were chosen at each site (Table 1; Figure 2; Cape Gris-Nez: GN1, GN2 and GN3; Audresselles: Aud1, Aud2 and Aud3). In the English Channel, tides are semidiurnal, rising and falling twice a day. Three pools - GN1, GN2 and Aud1 - were the highest pools on their respective shores, as no other pools occupied by G. gracilis were situated at a higher level. Accordingly, GN1, GN2 and Aud1 were designated as high-shore pools, while GN3, Aud2 and Aud3 were designated as low-shore pools (Figure 2). To characterize the differences in pools' relative emersion (exposure) times quantitatively, the mean percentage of time spent emerged was computed for each pool. The mean percentage of emersion time was calculated as the duration of emersion, according to height on the shore, divided by a 1-month time interval and averaged over a year using the SHOM database (Table 1) (http:// www.shom.fr/fr_page/fr_serv_prediction/ann_marees_f. htm, year 2001, Boulogne-sur-Mer district).

The characteristics of each study rock pool are listed in Table 1. While rock pools constitute a convenient topological definition of a population, in the larger pools, sampling was confined to a sector defined by the contours of the rock pool (pools Aud1 and GN3; Table 1), with the exception of GN1, which was so large that we sampled individuals along a $2 \mathrm{~m}$ wide transect spanning the length of the pool.

Ploidy and sexual phenotypes of all sampled individuals were determined by observing reproductive structures under a dissecting microscope. For each pool, the total sample was divided into diploid and haploid subsamples. Biological material was dried and three thallus tips of ca. $5 \mathrm{~mm}$ were later excised from each individual for DNA extraction.

\section{Analysis of microsatellite loci}

DNA extraction was performed according to Wattier et al (1997). Seven microsatellite loci (Gv2CT, Gg121, Gg155, Gg173, Gg182, Gg202 and Gg216) were used among those characterized for G. gracilis (Wattier et al, 1997; Luo et al, 1999). DNA samples were amplified according to the protocol in Luo et al (1999), with slight modifications for Gv2CT (Wattier et al, 1997). Although reports indicate that in many orders of red seaweeds, including Gracilariales, spores may coalesce and form a single, genetically chimeric plant (Santelices et al, 1999), no genotypes with supernumerary alleles were observed in this study.

\section{Data analyses}

Genetic and genotypic diversity: For each pool, we calculated the mean number of alleles per locus $\left(A_{\mathrm{O}}\right)$ and the average expected heterozygosity (nonbiased observed gene diversity, $H_{\mathrm{e}}$; Nei, 1978) for both haploid and diploid subsamples. The haploid and diploid subsamples represent different stages of the same life

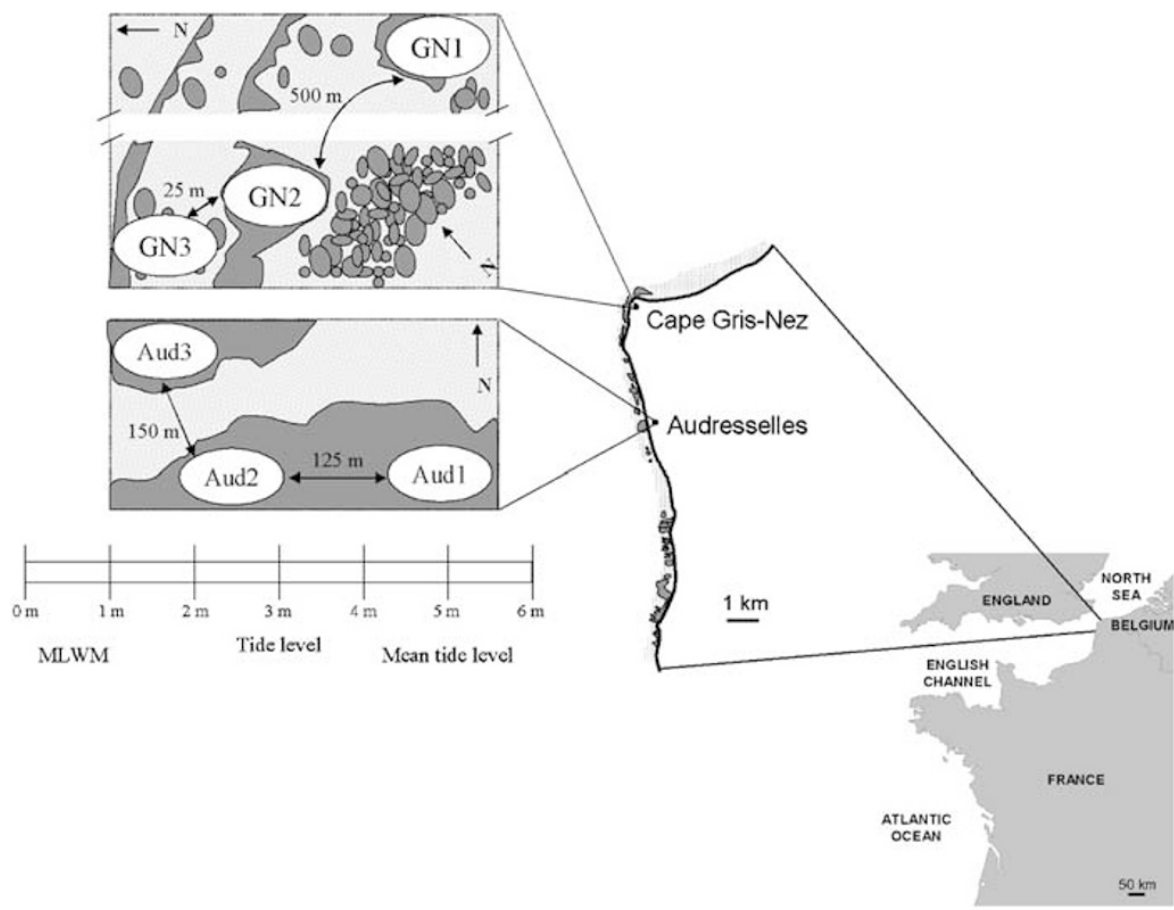

Figure 2 Schematic birds-eye view of the six study populations on the French coast of the Strait of Dover. Distances are not to scale in the insets. MLWM, mean low water mark, according to marine charts. Light grey areas, sand; dark grey areas, bedrock or rock outcrops. The tip of Cape Gris-Nez has a relatively steep shoreline, dominated by sandstone boulders arising from the eroding anticline cliff face, while Audresselles is made up of a long uneven stretch of exposed bedrock. Owing to their tide levels and to the terrain, GN1, GN2 and Aud1 were the highest populations observed on their respective shores. 
Table 1 Population characteristics

\begin{tabular}{|c|c|c|c|c|c|c|c|c|}
\hline Site & Pool & Tide level (m) & Time in emersion $(\% \pm S D)$ & Sampling protocol & $\mathrm{N}_{T}$ & $\mathrm{~N}_{S}$ & $\mathrm{~S}_{T}\left(m^{2}\right)$ & $\mathrm{S}_{S}\left(m^{2}\right)$ \\
\hline \multirow[t]{3}{*}{ Gris-Nez } & GN1 & 4.8 & $54 \pm 3$ & Transect & $292^{a}$ & 80 & 250 & 115 \\
\hline & GN2 & 2.8 & $35 \pm 4$ & Exhaustive: Pool & 169 & 169 & 5 & 5 \\
\hline & GN3 & 1.3 & $8 \pm 3$ & Exhaustive: Sector & $360^{\mathrm{b}}$ & 107 & 50 & 14 \\
\hline \multirow[t]{3}{*}{ Audresselles } & Aud1 & 4.9 & $62 \pm 4$ & Exhaustive: Sector & $227^{c}$ & 106 & 32 & 18 \\
\hline & Aud2 & 2.3 & $27 \pm 5$ & Exhaustive: Pool & 49 & 49 & 16 & 16 \\
\hline & Aud3 & 1.4 & $7 \pm 3$ & Exhaustive: Pool & 65 & 65 & 7.5 & 7.5 \\
\hline
\end{tabular}

Tide level, height on shore above chart datum (mean tide level in the Boulogne-sur-Mer district, $4.91 \mathrm{~m}$ ); time in emersion, mean percentage of time that a pool spends emerged (ie exposed). $N_{\mathrm{T}}$, total number of individuals (=plants) occupying the tide pool; $N_{\mathrm{S}}$, number of individuals sampled; $S_{\mathrm{T}}$, total surface of the tide pool; $S_{\mathrm{S}}$, area of the pool sector studied.

${ }^{\mathrm{a}}$ Number of individuals estimated from the density and surface area; the exact number is unknown.

${ }^{\mathrm{b}}$ Total number according to Destombe (1987).

${ }^{\mathrm{C}}$ Total number of individuals according to Richerd (1993).

cycle and, barring differential selection and/or asexual reproduction, should show similar genetic diversities and allele frequencies (eg Pamilo, 1993; Sosa et al, 1998). Differences in gene and allele diversities between haploid and diploid subsamples were tested using nonparametric Wilcoxon's signed-rank tests. To correct for allelic diversity differences due to disparities in the number of genes in haploid and diploid samples, an estimate of the mean expected number of alleles $\left(A_{\mathrm{E}}\right)$ in a sample containing $n_{i}$ genes given that $2 N_{i}$ genes have been sampled (where $n_{i}$ is the number of sampled haploid individuals and $N_{i}$ is the number of sampled diploid individuals in pool $i$ ) was computed following El Mousadik and Petit (1996). Finally, because, for diploid data, nonbiased $F_{\mathrm{ST}}$-based estimators depend on the observed numbers of heterozygotes (eg Weir and Cockerham, 1984), haploids - for which heterozygotes are meaningless - cannot be analyzed in the same data set as diploids. Thus, to test for differences in allele frequencies between ploidy levels within each pool, exact tests were performed on the distribution of allelic counts of both ploidy levels as provided in GENEPOP, ver. 3.1 (Raymond and Rousset, 1995).

To investigate the effect of the polyembryony-like process on genotypic diversity (ie the degree of recruitment of sister carpospores), the proportion of unique diploid genotypes within each population was calculated as $D^{*}$ (=number of unique diploid genotypes $\left./ N_{i}\right)$ (Ellstrand and Roose, 1987). To analyze the mating system, fixation indices $\left(\hat{f}_{\text {IS }}\right)$ within each pool were computed for each locus and heterozygote deficiencies and excesses were tested using 4200 randomizations of alleles among diploid individuals within each population using the FSTAT software package (Goudet, 1995). In FSTAT, the probability associated with the multilocus estimate is a function of the average of each locus' test statistic weighted according to its polymorphism, making for a more powerful test of multilocus $f_{\mathrm{IS}}$.

Mating system and population genetic structure: At equal effective population sizes $\left(N_{\mathrm{e}}\right)$ and migration rates $(m)$, differentiation in a haploid organism is roughly twice as great as in diploids (ie haploid differentiation: $\quad F_{\mathrm{STH}}=1 /\left[1+2 N_{\mathrm{e}} m\right]$ vs diploid differentiation: $\left.F_{\mathrm{STD}}=1 /\left[1+4 N_{\mathrm{e}} m\right]\right)$, since the presence of only one copy of each gene results in a stronger genetic drift. However, in a haploid-diploid organism, haploid and diploid $F_{\mathrm{ST}}$ values should be comparable, because haploid and diploid $F_{\mathrm{ST}}$ 's are governed by a unique effective population size. Indeed, the effective number of genes that contribute to the gene pool depends on the effective numbers of haploids and diploids; thus, $\quad F_{\mathrm{STH}}=F_{\mathrm{ST} \mathrm{D}}=1 /\left[1+2 N_{\mathrm{e}}\left(m_{\mathrm{H}}+m_{\mathrm{D}}\right)\right]$ (note that when haploid and diploid migration rates are equal, that is, where $m_{\mathrm{H}}=m_{\mathrm{D}}, F_{\mathrm{STH}}=F_{\mathrm{STD}}=1$ / $\left[1+4 N_{\mathrm{e}} m\right]$ ) (D Couvet, personal communication). We therefore expect to find similar among-population structure in haploid and diploid subsamples.

To test this hypothesis, population genetic structure was analyzed in haploid and diploid subsamples using a hierarchical analysis of gene frequencies (Weir, 1996); the genetic variance among individuals in the total sample $\left(F_{\mathrm{IT}}\right)$ due to correlation of genes within individuals within pools $\left(F_{\mathrm{IS}}\right)$ and to genetic differentiation among pools $\left(F_{\mathrm{ST}}\right) . F_{\mathrm{ST}}$ was further broken down into a poolwithin-sites component $\left(F_{\mathrm{SC}}\right)$ and an among-sites component $\left(F_{\mathrm{CT}}\right) \quad$ (where $\left.1-F_{\mathrm{ST}}=\left(1-F_{\mathrm{SC}}\right)\left(1-F_{\mathrm{CT}}\right)\right)$. These $F$-statistics were estimated using the Weir and Cockerham (1984) estimators $\hat{F}_{\mathrm{IT}}, \hat{f}_{\mathrm{IS}}, \hat{\theta}_{\mathrm{ST}}, \hat{\theta}_{\mathrm{SC}}$ and $\hat{\theta}_{\mathrm{CT}}$. For the haploid subsample, only $\hat{\theta}_{\mathrm{ST}}, \hat{\theta}_{\mathrm{SC}}$ and $\hat{\theta}_{\mathrm{CT}}$ are meaningful. The permutation procedures provided in the AMOVA option of Arlequin (Schneider et al, 2000) allowed us to test the deviation from zero of both singleand multilocus estimates of the three-level hierarchical F-statistics. For diploids, as $\hat{\theta}_{\mathrm{ST}}$ is not provided in Arlequin when the within-individual level is included, deviation from zero for each locus was tested using the method of Workman and Niswander (1970); for the multilocus estimate, the single-locus probabilities were combined using Fisher's procedure. Finally, to assess the precision and the degree of overlap of the haploid and diploid multilocus estimates, $95 \%$ confidence intervals were obtained from the distribution of replicates generated by bootstraping over loci 1000 times using the GDA software package (Lewis and Zaykin, 2001).

Finally, to illustrate the patterns observed in the hierarchical analysis, pairwise (ie between pools) $\hat{\theta}_{\mathrm{ST}}$ values were calculated using FSTAT for both the haploid and diploid subsamples. As the pattern of pairwise differentiation was expected to be similar in both stages, the correlation of haploid and diploid pairwise $\hat{\theta}_{\text {ST }}$ values was tested using the Mantel test provided in GENEPOP (10000 permutations). 
Assignment test: Relying on fast-decaying linkage disequilibrium, assignment tests are powerful methods for detecting (recent) immigration events, even when overall differentiation, a product of long-term processes, among populations is low (Rannala and Mountain, 1997; Waser and Strobeck, 1998). Assignment tests are particularly pertinent in landscape approaches of gene flow as the patterns of misclassification can be used to determine the direction of migration among populations. Genetic-based classification methods are based on straightforward allele frequencies or genetic distances (Cornuet et al, 1999); however, software currently available for implementing these methods implicitly require separate treatment of haploids and diploids. Wishing to create a synthetic genetic signature of populations where classification would be based on allele configurations of both haploid and diploid individuals simultaneously, we used a classical multivariate method. Classical multivariate analysis generates a set of functions from which individuals are assigned to specific populations and have been successfully used as assignment methods in population genetics studies (cf. Taylor et al, 1994; Cornuet et al, 1996). Here, we employed the discriminant function analysis (DFA), as implemented in STATISTICA (Statsoft Inc., 1995), to estimate linear functions using every allele at all seven loci as predictor variables and pools as the group classification variable. Individuals were coded 0,1 or 2 for each variable, according to the number of allele copies observed. Thus, haploids contributed one allele per locus and diploids two, thereby describing true population-wide allele frequencies that constituted the genetic signature of each pool. To avoid autocorrelation among variables, the most frequent allele in each locus was removed from the data set. To obtain the most robust genetic signature, individuals missing information at one or more loci were removed from the data set.

\section{Results}

\section{Gene diversity and structure within pools}

Gene diversity: Overall, 49 and 58 alleles were observed in the 280 haploid individuals and 296 diploid individuals, respectively. Two loci, Gv2CT and Gg121, were highly polymorphic with 20 and 16 alleles, respectively, while the other five loci showed from four to eight alleles. Allele frequencies of haploid and diploid subsamples of each pool are available upon request. Within pools, the expected heterozygosities $\left(H_{\mathrm{e}}\right)$ were moderately high and varied little, ranging from 0.393 to 0.544 (Table 2). Pool by pool, $H_{\mathrm{e}}$ values were similar in haploid and diploid subsamples (bilateral Wilcoxon's signed-rank test, $T=12, n=6, P=0.83$ ). Likewise, when adjusted to haploid sample sizes, the numbers of alleles were not significantly different between diploids and haploids (bilateral Wilcoxon's signed-rank test, $T=2$, $n=6, P=0.09$ ). Moreover, none of the pools showed significant differences in allele frequencies (after Bonferroni correction) between the haploid and diploid stages (Table 2).

Genotypic diversity and mating system: Genotypic diversity was generally high but variable. Although all populations showed at least one shared multilocus diploid genotype, in two populations, GN2 and Aud1, the proportion of shared genotypes $\left(1-D^{*}\right)$ was substantially greater than $5 \%$ (Table 3 ). Genotypes were shared by at most two individuals except in the Aud1 pool where up to five individuals possessed the same multilocus genotype (data not shown).

None of the single- or multilocus $f_{\text {IS }}$ estimates were significantly different from zero in any population (multilocus estimates, Table 3; single-locus estimates not shown). The low jackknife standard errors indicate that the loci were generally concordant. The two populations with the highest proportions of shared genotypes (GN2 and Aud1) showed estimates similar to the other populations.

Patterns of among-population genetic structure: The hierarchical analyses of genetic structure appear in Table 4 . Single-locus $\hat{f}_{\mathrm{IS}}$ values were generally negative, but only Gg173 was significantly so. The multilocus $\hat{f}_{\text {IS }}$ value was negative, but only marginally significant: permutation tests indicated a $P$-value of 0.036 , while the 95\% confidence interval indicated that the multilocus $\hat{f}_{\mathrm{IS}}$ value was not significantly different from zero (see Table 4$). \hat{F}_{\text {IT }}$ values oscillated around zero and the overall genetic variance among individuals was not significantly greater than zero. This indicates that the negative correlation of alleles within individuals within pools

Table 2 Within-pool gene and allelic diversities according to the ploidy level

\begin{tabular}{|c|c|c|c|c|c|c|c|c|}
\hline \multirow[t]{2}{*}{ Pool } & \multicolumn{4}{|c|}{ Diploid } & \multicolumn{3}{|c|}{ Haploid } & \multirow{2}{*}{$\begin{array}{c}\Delta \\
\text { P-value }\end{array}$} \\
\hline & $\mathrm{N}$ & $\mathrm{H}_{e}$ & $\mathrm{~A}_{O}$ & $\mathrm{~A}_{E}$ & $N$ & $\mathrm{H}_{\mathrm{e}}^{\mathrm{a}}$ & $\mathrm{A}_{O}$ & \\
\hline GN1 & 37 & $0.516(0.077)$ & $4.286(0.778)$ & 3.981 & 43 & $0.493(0.067)$ & $4.143(0.857)$ & 0.233 \\
\hline GN2 & 76 & $0.514(0.071)$ & $5.714(1.584)$ & 5.169 & 93 & $0.481(0.073)$ & $5.714(1.475)$ & 0.032 \\
\hline GN3 & 61 & $0.512(0.078)$ & 5.857 (1.335) & 4.578 & 46 & $0.544(0.073)$ & $4.429(0.841)$ & 0.273 \\
\hline Aud1 & 66 & $0.456(0.073)$ & $4.286(0.778)$ & 3.569 & 40 & $0.393(0.100)$ & $3.714(0.747)$ & 0.035 \\
\hline Aud2 & 26 & $0.501(0.067)$ & $4.000(0.873)$ & 3.252 & 23 & $0.540(0.071)$ & $3.857(0.884)$ & 0.788 \\
\hline Aud3 & 30 & $0.462(0.087)$ & $4.143(0.962)$ & 3.699 & 35 & $0.472(0.090)$ & $4.000(0.724)$ & 0.928 \\
\hline
\end{tabular}

$N$, number of sampled individuals, note that for diploids, $2 N$ genes were sampled; $H_{\mathrm{e}}$ (SE), gene diversities (Nei's (1978) nonbiased estimator); $A_{\mathrm{O}}(\mathrm{SE})$, average observed number of alleles; $A_{\mathrm{E}}$, estimates of expected diploid allelic richness based on haploid subsample size from the same pool. $\Delta$, differences in allele frequencies between haploids and diploids of the same pool; $P$-value, probability associated with Fisher's exact test combined across loci on contingency tables of observed haploid and diploid allele distribution, none of the values are significant (Bonferroni-corrected threshold $P$-value $=0.007$ for $\alpha=0.05$ )

an haploids, $H_{\mathrm{e}}$ was corrected by a factor of $(2 N-1) /(2 N-2)$. 
$\left(\hat{f}_{\mathrm{IS}}\right)$ was roughly of the same magnitude as the positive correlation among individuals $\left(\hat{\theta}_{\mathrm{ST}}\right)$ of a pool.

For both haploid and diploid samples, single- and multilocus $\hat{\theta}_{\mathrm{ST}}$ estimates were low; nevertheless, more than half of the single-locus estimates were significantly positive, as were the multilocus estimates (Table 4). Single-locus haploid estimates were equal to or greater than diploid estimates and the overall differentiation among haploids was 2.3 times greater than among diploids. Indeed, the $95 \%$ confidence intervals of the haploid and diploid estimates overlapped only slightly (Table 4) and the observed haploid and diploid allele distributions over all populations were significantly different (Fisher's exact test combined across loci, $P=0.027)$.

Examining the relative levels of differentiation within and between sites showed that differentiation among pools within sites $\left(\hat{\theta}_{\mathrm{SC}}\right)$ was significant, while differentiation between sites $\left(\hat{\theta}_{\mathrm{CT}}\right)$ was not (Table 4$)$, although for diploids, $95 \%$ confidence intervals appeared to indicate marginal significance. Accordingly, genetic differentiation did not increase with greater geographical distance among subdivisions. For both haploids and diploids, differentiation among pools $25-500 \mathrm{~m}$ apart was not different from that among sites $5 \mathrm{~km}$ apart (cf. overlapping $95 \% \mathrm{CI}$, Table 4).

Pairwise $\hat{\theta}_{\mathrm{ST}}$ values (Table 5) illustrate the patterns discerned with hierarchical analysis. Differentiation

Table 3 Genotypic diversity and mating system

\begin{tabular}{llllr}
\hline Pool & $\mathrm{N}$ & $\mathrm{N}_{G}$ & $\mathrm{D}^{*}$ & \multicolumn{1}{c}{$\hat{\mathrm{f}}_{I S}$} \\
\hline GN1 & 37 & 35 & 0.946 & $0.040(0.015)$ \\
GN2 & 76 & 69 & 0.908 & $-0.054(0.021)$ \\
GN3 & 61 & 60 & 0.984 & $-0.029(0.015)$ \\
Aud1 & 66 & 58 & 0.879 & $-0.042(0.021)$ \\
Aud2 & 26 & 25 & 0.962 & $-0.072(0.015)$ \\
Aud3 & 30 & 29 & 0.967 & $0.005(0.015)$ \\
\hline
\end{tabular}

$N$, number of diploid individuals sampled; $N_{\mathrm{G}}$, number of unique diploid multilocus genotypes observed; $D^{*}$, proportion of unique diploid genotypes; $f_{\mathrm{IS}}$, multilocus value; none of the values were significant at $P<0.001(\alpha=0.05)$; jackknife standard errors are given in parentheses. among pools of different sites was not systematically greater than within-site differentiation. The lowest values were associated with low-shore (GN3, Aud2 and Aud3) pools regardless of whether they belonged to the same or different sites (Table 5). The highest (and significant) values always implicated the GN2, Aud1 and, to a lesser degree, GN1 pools, both within and between sites (Table 5). Finally, values were not correlated between haploid and diploid pairwise $\hat{\theta}_{\mathrm{ST}^{\prime}}{ }^{\prime} \mathrm{S}$ (Spearman's rank coefficient, $r_{\mathrm{S}}=0.432$, Mantel test, $P=0.143)$, indicating that the relative ranking of interpopulation genetic differentiation was discordant in the two stages.

With 261 haploids and 269 diploids, the DFA resulted in three significant functions, accounting for a total of $80 \%$ of variation between pools: the first function explained $45.0 \%$ of the variability $(P<0.001)$, the second, $20.0 \%(P<0.001)$ and the third, 15.6\% $(P=0.002)$. Based on these functions, individuals were assigned to one of the six study pools (Table 6). Haploids and diploids showed identical classification patterns: classifying the two stages according to assignment to (1) the pool of origin (haploids, $44.8 \%$; diploids, $48.3 \%$ ), (2) another pool in the site of origin (haploids, $26.4 \%$; diploids, $27.5 \%$ ) or (3) the other site (haploids, $28.7 \%$; diploids, $24.2 \%)(2 \times 3$ contingency table, Fisher's exact test, $P=0.493)$. Thus haploids and diploids were considered together in the following analysis. Classifying individuals from

Table 5 Genetic differentiation between pairs of populations according to the ploidy level

\begin{tabular}{lccclcr}
\hline & GN1 & GN2 & GN3 & \multicolumn{1}{c}{$A u d 1$} & Aud2 & Aud3 \\
\hline GN1 & & 0.0153 & 0.0268 & $0.1010^{* *}$ & 0.0477 & 0.0310 \\
GN2 & $0.0075^{* *}$ & & 0.0056 & 0.0501 & 0.0316 & 0.0028 \\
GN3 & -0.0032 & $0.0120^{* *}$ & & $0.0718^{* *}$ & 0.0176 & -0.0023 \\
Aud1 & $0.0178^{* *}$ & $0.0272^{* *}$ & $0.0186^{* *}$ & & 0.0352 & $0.0331^{*}$ \\
Aud2 & $0.0020^{*}$ & $0.0143^{*}$ & 0.0008 & $0.0023^{* *}$ & & 0.0022 \\
Aud3 & 0.0065 & $0.0145^{* *}$ & 0.0024 & $0.0084^{* *}$ & 0.0009 & \\
\hline
\end{tabular}

Multilocus $\hat{\theta}_{\mathrm{ST}}$ values are given for between-haploid samples (above the diagonal) and for between-diploid samples (below the diagonal). Between-site values are given in italics.

${ }^{*} P<0.05 ;{ }^{* *} P<0.01$; significance levels were adjusted using Bonferroni correction provided in FSTAT.

Table 4 Partitioning of genetic diversity within and among pools and sites according to the ploidy level

\begin{tabular}{|c|c|c|c|c|c|c|c|c|}
\hline \multirow[t]{2}{*}{ Locus } & \multicolumn{5}{|c|}{ Diploid } & \multicolumn{3}{|c|}{ Haploid } \\
\hline & $\hat{F}_{I T}$ & $\hat{\mathrm{f}}_{I S}$ & $\hat{\theta}_{S T}^{\mathrm{a}}$ & $\hat{\theta}_{S C}$ & $\hat{\theta}_{C T}$ & $\hat{\theta}_{S T}$ & $\hat{\theta}_{S C}$ & $\hat{\theta}_{C T}$ \\
\hline Gv2CT & 0.032 & -0.012 & $0.015^{* * *}$ & $0.012^{* *}$ & 0.003 & $0.032^{* * *}$ & $0.022^{*}$ & 0.011 \\
\hline Gg121 & 0.011 & -0.001 & $0.013^{* *}$ & 0.006 & 0.007 & $0.076^{* * *}$ & 0.016 & 0.061 \\
\hline Gg155 & -0.029 & -0.062 & $0.031^{* * *}$ & $0.016^{*}$ & 0.015 & 0.017 & 0.024 & -0.007 \\
\hline Gg173 & $-0.100^{* *}$ & $-0.109^{* *}$ & 0.011 & -0.003 & 0.013 & 0.009 & 0.003 & 0.007 \\
\hline Gg182 & 0.035 & -0.021 & $0.020^{* * *}$ & 0.003 & 0.017 & $0.020^{*}$ & $0.030^{*}$ & -0.010 \\
\hline Gg202 & 0.002 & 0.004 & -0.001 & 0.003 & -0.004 & -0.007 & -0.001 & -0.006 \\
\hline Gg216 & -0.037 & -0.051 & $0.015^{* *}$ & 0.002 & 0.013 & $0.080^{* * *}$ & 0.023 & 0.059 \\
\hline $\begin{array}{l}\text { Multilocus } \\
95 \% \text { CI }\end{array}$ & $\begin{array}{c}-0.014 \\
{[-0.052,0.018]}\end{array}$ & $\begin{array}{c}-0.030^{*} \\
{[-0.068,0.001]}\end{array}$ & $\begin{array}{c}0.016^{* * *} \\
{[0.011-0.021]}\end{array}$ & $\begin{array}{c}0.006^{*} \\
{[0.001,0.011]}\end{array}$ & $\begin{array}{c}0.010 \\
{[0.005,0.014]}\end{array}$ & $\begin{array}{c}0.037^{* * *} \\
{[0.015-0.059]}\end{array}$ & $\begin{array}{c}0.017^{* *} \\
{[0.009}\end{array}$ & $\begin{array}{r}0.020 \\
-0.001\end{array}$ \\
\hline
\end{tabular}

Three-level hierarchical single- and multilocus F-statistics; estimators are defined in the Materials and methods section. ${ }^{*} P<0.05$; ${ }^{* *}, P<0.01$; $* * *, P<0.001$, where $P$ is the probability associated with AMOVA permutation tests. $95 \% \mathrm{CI}, 95 \%$ confidence intervals generated by bootstrapping over the loci.

aSignificance of single-locus values tested using the Workman and Niswander (1970) method, mulitlocus sT tested using Fisher's combined probabilities method. 
Table 6 Assignment of individuals to pools

\begin{tabular}{|c|c|c|c|c|c|c|c|c|c|c|c|c|c|c|c|c|c|c|}
\hline \multirow[t]{3}{*}{ Assigned to } & \multicolumn{18}{|c|}{ Population of origin: } \\
\hline & \multicolumn{3}{|c|}{ GN1 } & \multicolumn{3}{|c|}{ GN2 } & \multicolumn{3}{|c|}{ GN3 } & \multicolumn{3}{|c|}{ Aud1 } & \multicolumn{3}{|c|}{$A u d 2$} & \multicolumn{3}{|c|}{ Aud3 } \\
\hline & $D$ & $H$ & $\%$ & $D$ & $H$ & $\%$ & $D$ & $H$ & $\%$ & $D$ & $H$ & $\%$ & $D$ & $H$ & $\%$ & $D$ & $H$ & $\%$ \\
\hline GN1 & 16 & 22 & 59.4 & 14 & 11 & 14.9 & 8 & 7 & 16.1 & 2 & 1 & 3.0 & 3 & 5 & 18.6 & 7 & 3 & 16.4 \\
\hline GN2 & 3 & 7 & 15.6 & 36 & 45 & 48.2 & 8 & 7 & 16.1 & 1 & 2 & 3.0 & 0 & 0 & 0 & 1 & 8 & 14.8 \\
\hline GN3 & 1 & 0 & 1.6 & 5 & 7 & 7.1 & 16 & 13 & 31.2 & 1 & 2 & 3.0 & 1 & 0 & 2.3 & 3 & 1 & 6.6 \\
\hline Aud1 & 0 & 0 & 0 & 3 & 4 & 4.2 & 5 & 3 & 8.6 & 38 & 17 & 54.5 & 4 & 4 & 18.6 & 1 & 3 & 6.6 \\
\hline Aud2 & 5 & 2 & 10.9 & 10 & 10 & 11.9 & 6 & 5 & 11.8 & 17 & 4 & 20.8 & 12 & 9 & 48.8 & 5 & 6 & 18.0 \\
\hline Aud3 & 3 & 5 & 12.5 & 8 & 15 & 13.7 & 6 & 9 & 16.1 & 6 & 10 & 15.8 & 2 & 3 & 11.6 & 12 & 11 & 37.7 \\
\hline Total & 28 & 36 & & 76 & 92 & & 49 & 44 & & 65 & 36 & & 22 & 21 & & 29 & 32 & \\
\hline
\end{tabular}

Classification table generated by discriminant function analysis: assignment of diploid (D) and haploid (H) individuals to the six study populations based on population-wide allele frequencies; \%, percentage of individuals of a pool assigned to each of the six study pools.

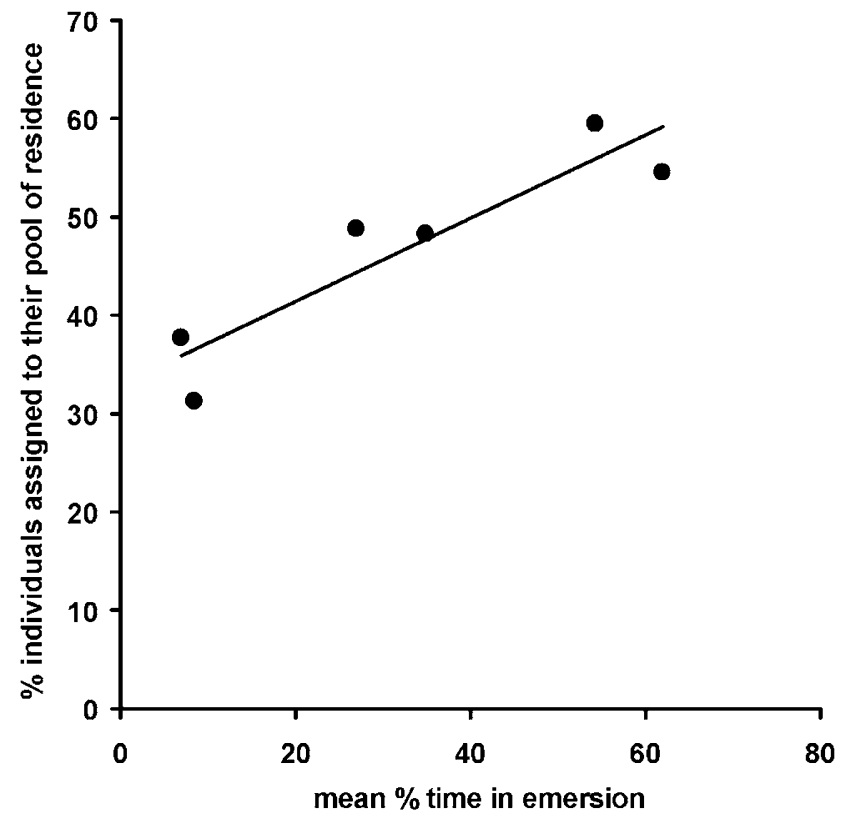

Figure 3 Assignment to pool of residence according to emersion time. \% individuals assigned to their pool of residence, based on the results of assignment test and expressed as the percentage of individuals from a given pool assigned to that pool; mean \% of time in emersion, mean percentage of time that a given pool spends emerged (ie isolated from pools downstream). The regression has a significantly positive slope $(\%$ individuals assigned $=33.1+0.422$ mean \% time in emersion; $P=0.01$ ).

high-shore pools (GN1, GN2, Aud1) and low-shore pools (GN3, Aud2, Aud3), according to correct and incorrect assignments, showed that high-shore individuals were more frequently assigned to their original pools $(52.3 \%)$ than low-shore individuals $(37.1 \%)(2 \times 2$ table, $P<0.001)$. Moreover, regressing the mean percentage of emersion time on the percentage of individuals assigned to their original pools revealed a significantly positive relationship (Figure 3, $R^{2}=0.84, P=0.01$ ), demonstrating that height on the shore significantly influenced migration among pools.

\section{Discussion}

In this study, we have shown that, in the haploid-diploid red seaweed G. gracilis, reproduction was predominantly sexual and gamete unions occur in an allogamous manner. In addition, we demonstrated that population differentiation, although weak, was significant and varied according to height on the shore and not with geographic distance. These results are discussed in light of possible sources of the observed patterns of genetic diversity: (1) haploid-diploid life cycle; (2) intertidal landscape; and (3) demographic causes of high genetic diversity and migration-drift disequilibrium.

\section{Sexual reproduction and the haploid-diploid life cycle} Haploid and diploid genetic and genotypic diversity: Within populations, we observed no significant differences in allele frequencies, gene diversities or mean numbers of alleles between haploids and diploids. Indeed, in species with diploid and haploid individuals, at mutation-drift equilibrium and assuming selective neutrality, Mendelian segregation and panmixia, allele frequencies (and thus gene diversities) are expected to be equal at both ploidy levels (Pamilo, 1993; Coyer et al, 1994; Sosa et al, 1998). However, only a few studies have explicitly compared haploid and diploid genetic diversity (eg moss, Innes, 1990; Shaw, 1991; ant, Pamilo, 1993; seaweeds, Wattier et al, 1997; Sosa et al, 1998; van der Strate et al, 2002). In seaweeds, the observed differences were attributed to the preponderance of vegetative propagation in comparison to the recruitment of individuals via sexual spores (Sosa et al, 1998; see also, van der Strate et al, 2002). Within G. gracilis populations, the lack of detectable differences in allele frequencies shows that recruitment occurred essentially through sexual reproduction.

The regular occurrence of germination of spores originating from the same cystocarp was not appreciable in our G. gracilis populations. As in polyembryonic organisms, such as the whitebark pine (Rogers et al, 1999), identical genotypes did occur within G. gracilis populations, but at relatively low levels $\left(0.88 \leqslant D^{*} \leqslant 0.97\right.$, Table 3) compared to clonal plants (mean $D^{*}=0.62$, Ellstrand and Roose, 1987). In addition, identical genotypes may actually attest to variance in haploid reproductive success. In haploid-diploid species, as gametes are produced by mitosis, zygotic spores resulting from independent gamete unions of a particular male-female couple are indistinguishable from spores resulting from the zygotic amplification of a single gamete union. Indeed, paternity analysis in the GN2 
population showed that while multiple paternity was prevalent, independent repeated gamete unions did occur (Engel et al, 1999).

Mating system and the haploid-diploid life cycle: In dioecious species, under random mating, a slight excess of heterozygotes is expected within populations (Cockerham, 1973). Accordingly, the single-locus $\hat{f}_{\text {IS }}$ values were generally negative and the multilocus estimate was only marginally significant (Table 4), indicating that mating among haploids was essentially random. Further, the absence of a Wahlund effect (ie heterozygote deficiencies) indicates that the study pools were not subdivided into distinct demes. Thus, the topological definition of a population - the tide pool did indeed constitute the panmictic unit, even in the largest pool (GN1), sampled over a $60 \mathrm{~m}$ transect.

The haploid-diploid life cycle of G. gracilis allowed us to test the theoretical predictions that endogamous mating systems are correlated with the maintenance of a prolonged haploid phase (Otto and Goldstein, 1992; Otto and Marks, 1996). However, contrary to this expectation for haploid-diploid organisms, in this study, G. gracilis was clearly allogamous. Moreover, in this species, the degree of mating between sibling gametophytes in this species is probably minimized by extensive gene flow (see below). Consequently, the 'purging hypothesis' does not seem to explain the maintenance of a prolonged haploid phase in this seaweed. Alternative models of the evolution and maintenance of haploid-diploid life cycles invoke factors other than purging of deleterious mutations that may promote biphasic life histories: niche differentiation in the two phases (Hughes and Otto, 1999), reduction of the cost of sex (Richerd et al, 1993a). Therefore, sexual reproduction and even outcrossing may not necessarily be contradictory to the maintenance of a haploid-diploid life cycle.

\section{Patterns of genetic differentiation: life cycle and habitat effects}

Discrepancies in haploid and diploid differentiation: Although within-population allele frequencies were similar between haploid and diploid subsamples, the overall genetic differentiation among haploid subsamples was more than twice that of diploid subsamples (Table 4). This result was all the more unexpected, as similar values of differentiation were expected due to the obligatory passage of all genes through haploid and diploid free-living stages. There are several possible explanations for this discrepancy. First, differential selection between the two ploidy levels may have negative effects on effective haploid migration. Nonetheless, microsatellite loci are generally thought to be selectively neutral. In addition, although differential selection between haploids (males) and diploids (females) has been detected in haplodiploid insects (Pamilo, 1993; Parker and Hedrick, 2000), we did not observe any significant differences in haploid and diploid within-population allele frequencies, suggesting the absence of strong differential selection at our microsatellite, or closely linked, loci. Second, migrationdrift disequilibrium is the most plausible explanation in agreement with our results: since pairwise genetic differentiation between pools was not correlated between the two ploidy levels (Table 5), there may be a lag between migration and (local) breeding due to the long generation times in G. gracilis ( $>20$ years, Engel et al, 2001). Finally, in the case of migration-drift disequilibrium, differential migration rates of haploid and diploid spores could account for the higher haploid $\hat{\theta}_{\mathrm{ST}}$ values. However, in vitro, haploid spores have better dispersal capacities than diploid spores (Destombe et al, 1992), indicating that haploid differentiation would be weaker than diploid differentiation. Our results suggested the opposite pattern: effective migration appeared more restricted in haploids. While the difference between potential and effective dispersal capacities may be due to a variety of biological, demographic or genetic factors, the inconsistency of in vitro and in situ results may simply arise from considerable male gamete dispersal. As the differentiation of the diploid phase is a product of both carpospore and gamete dispersal, differences in spore dispersal capacities may be attenuated or even reversed in G. gracilis, where at least $10 \%$ of effective male gametes disperse among pools (Engel et al, 1999).

Variation in the landscape and asymmetrical migration: The low estimates of $\hat{\theta}_{\mathrm{ST}}$ and the absence of a clear pattern of isolation-by-distance (within or between sites) indicate either high levels of (ongoing) gene flow and/or that populations are not at migrationdrift equilibrium (Slatkin, 1993). The difference in the magnitude of haploid and diploid $\hat{\theta}_{\mathrm{ST}}$ estimates suggested migration-drift disequilibrium, but the current gene flow may be far from negligible. A direct estimate of gene flow via paternity analysis in the GN2 pool indicated that $9 \%$ of male gametes originated outside the pool (Engel et al, 1999). Nevertheless, if, at this microgeographic scale, isolation-by-distance processes did not predominate genetic structuring, this does not imply that these processes are not important in G. gracilis, only that they are probably scale dependent. In fact, $\hat{\theta}_{\mathrm{ST}}$ in $G$. gracilis does increase linearly with distance at spatial scales of hundreds of kilometers (Engel et al, 1997).

In this study, genetic differentiation was associated with habitat type: only high-shore pools (ie GN2 and Aud1) were significantly differentiated from other pools (Table 6); in addition, significant spatial structure and lower genotypic diversity, signs of relative isolation, were only observed in high-shore pools. Rousset (1999) demonstrated that, in the case of asymmetric dispersal, differentiation between two habitats is always intermediate to that within each habitat. Indeed, $\hat{\theta}_{\mathrm{ST}}$ values were generally low between low-shore pools, high between high-shore pools and intermediate between high- and low-shore pools (Table 5). More strikingly, spatial variation in migration rates was revealed (Figure 3), showing that the percentage of resident (ie autorecruited, nonmigrant) individuals increased significantly with the duration of emersion time (ie time during which the study pool is isolated from other pools of the same shore).

In other intertidal species, genetic differences between high- and low-shore populations have been attributed to fitness differences, either owing to differential selection pressures (green seaweed, Innes, 1988) or to higher 
extinction probabilities (seagrass, Ruckelshaus, 1998). However, a demographic study of Aud1, Aud2, GN2 and GN3 revealed similar population dynamics in all the pools (Engel et al, 2001). In the absence of differences in survival, fecundity or extinction probabilities and even habitat quality, biased spore dispersal may generate directional gene flow (cf. Stanton et al, 1997; Kawecki and Holt, 2002). If the transport of spores and gametes occurs predominantly at low tide when small streams flow from high- to lower-shore pools, higher pools will be relatively isolated from gene flow compared to lower pools. Highshore populations are physically isolated from the sea daily. On the other hand, low-shore pools are more often submerged than emerged; therefore, they are open to migrants, not only from run-off from higher pools but also from pools at the same shore level. An experimental study in G. gracilis showed that fertilization occurred essentially at low tide in high-shore pools, while lowshore pools showed similar fertilization rates during high- and low-tide periods (Engel and Destombe, 2002). These differences according to height on the shore suggest, as this study clearly demonstrated (see Figure 3), that high-shore pools receive few extrapopulation gametes, while low-shore pools receive a substantial proportion of immigrant gametes. Thus, together, these results show that the intertidal landscape imposes asymmetrical migration between high- and low-shore pools, and suggests that limited gene flow into highshore pools could promote local adaptation to high-shore ecophysiological conditions (eg large daily fluctuations in temperature, salinity, luminosity, etc).

\section{Maintaining high genetic diversity in a haploid-diploid species}

The overall genetic structure was relatively weak in $G$. gracilis at this microgeographic scale, revealing high within-population diversity and substantial migration among populations. A recent model showed that drift is a weak force in the population genetic structure of trees typically long lived with long juvenile phases - because new migrants arrive before (founding) individuals contribute to the gamete pool (Austerlitz et al, 2000). In light of this model, the high survival rates and long generation times typical of G. gracilis populations (Engel et al, 2001) probably help maintain high genetic diversity within populations (relative to among populations). Similarly, according to the 'storage effect', genetic drift is buffered in long-lived organisms due to the storage of genotypes in long-lived stages (Gaggiotti and Vetter, 1999; see also, Ellner and Hairston, 1994), much as a seed bank slows down coalescence rates (Kaj et al, 2001). Thus, the alternance of independent, obligatory, perennial haploid and diploid phases through which all genes transit may very well contribute to the maintenance of high genetic variability.

\section{Acknowledgements}

We thank S Faugeron, E Martinez, H Luo, V Laporte, F Wozniak, P Lemaire for invaluable help in the field, J-F Allienne and C Pionneau for technical assistance in the lab and J Goudet, D Jollivet and F Viard for helpful comments. This study was supported by European Commission research contract MAS3-CT95-0019 (BIO-
GAP), the Nord-Pas de Calais Region (DYSCOP II), European Funds for Regional Development (FEDER), the Bettencourt-Schueller Foundation (Coup d'élan 2001) and a PhD fellowship (no. 10556) from the French Ministry of Foreign Affairs to CRE

\section{References}

Austerlitz F, Mariette S, Machon N, Gouyon P-H, Godelle B (2000). Effects of colonization processes on genetic diversity: differences between annual plants and tree species. Genetics 154: 1309-1321.

Bohonak AJ (1999). Dispersal, gene flow, and population structure. $Q$ Rev Biol 74: 21-45.

Brown AHD, Clegg MT, Kahler AL, Weir BS (1990). Plant genetic diversity. Trends Ecol Evol 6: 265-266.

Cockerham CC (1973). Analyses of gene frequencies. Genetics 74: 679-700.

Cornuet J-M, Aulagnier S, Lek S, Franck P, Solignac M (1996). Classifying individuals among infra-specific taxa using microsatellite data and neural networks. C R Acad Sci Paris 319: 1167-1177.

Cornuet J-M, Piry S, Luikart G, Estoup A, Solignac M (1999). New methods employing multilocus genotypes to select or exclude populations as origins of individuals. Genetics 153: 1989-2000.

Coyer JA, Robertson DL, Alberte RS (1994). Genetic variability within a population and between diploid/haploid tissue of Macrocystis pyrifera (Phaeophyceae). J Phycol 30: 545-552.

Craig SF, Slobodkin LB, Wray GA, Biermann CH (1997). The paradox of polyembryony: a review of the cases and a hypothesis for its evolution. Evol Ecol 11: 127-143.

Destombe C (1987). Biologie des populations de l'algue rouge Gracilaria verrucosa Hudson (Papenfuss) (Gigartinales), intérêt et implication en aquaculture. Ph.D. Thesis, de l'Université des Sciences et Techniques de Lille Flandres-Artois.

Destombe C, Godin J, Lefebvre CL, Dehorter O, Vernet P (1992). Differences in dispersal abilities of haploid and diploid spores of Gracilaria verrucosa (Gracilariales, Rhodophyta). Bot Mar 35: 93-98.

El Mousadik A, Petit RJ (1996). High level of genetic differentiation for allelic richness among populations of the argan tree (Argania spinosa (L.) Skeels) endemic to Morocco. Theor Appl Genet 92: 832-839.

Ellner S, Hairston NG (1994). Role of overlapping generations in maintaining genetic variation in a fluctuating environment. Am Nat 143: 403-417.

Ellstrand NC, Roose ML (1987). Patterns of genotypic diversity in clonal plant species. Am J Bot 74: 123-131.

Engel CR, Ảberg P, Gaggiotti O, Destombe C, Valero M (2001). Population dynamics and stage structure in a red haploiddiploid red seaweed, Gracilaria gracilis. J Ecol 89: 436-450.

Engel CR, Destombe C (2002). Reproductive ecology of an intertidal red seaweed, Gracilaria gracilis: influence of high and low tides on fertilization success. J Mar Biol Assoc UK 37: 189-192.

Engel CR, Wattier R, Destombe C, Valero M (1997). Dispersal in a haplo-diploid red algal species: genetic structure and gene flow in Gracilaria gracilis. Vie Milieu-Life Environ 47: 333-337.

Engel CR, Wattier R, Destombe C, Valero M (1999). Performance of non-motile male gametes in the sea: analysis of paternity and fertilization success in a natural population of a red seaweed, Gracilaria gracilis. Proc $R$ Soc London, Ser B 266 $1879-1886$.

Féral J-P (2001). How useful are the genetic markers in attempts to understand and manage marine biodiversity? J Exp Mar Biol Ecol 268: 121-145.

Gaggiotti OE, Vetter RD (1999). Effect of life history strategy, environmental variability, and overexploitation on the genetic diversity of pelagic fish populations. Can J Fish Aquat Sci 56: 1376-1388. 
Goudet J (1995). FSTAT (ver. 1.2): a computer program to calculate F-statistics. J Hered 86: 485-486.

Hamrick JL, Godt MJW (1997). Effects of life history traits on genetic diversity in plant species. In: Silvertown J, Franco M, Harper JL (eds) Plant Life Histories: Ecology, Phylogeny, and Evolution, Cambridge University Press: Cambridge.

Hawkes MW (1990). Reproductive strategies. In: Cole KM, Sheath RG (eds) Biology of the Red Algae, Cambridge University Press: Cambridge pp 455-476.

Hughes JS, Otto SP (1999). Ecology and the evolution of biphasic life cycles. Am Nat 154: 306-320.

Innes DJ (1988). Genetic differentiation in the intertidal zone in populations of the alga Enteromorpha linza (Chlorophyta, Ulvales). Mar Biol 97: 9-16.

Innes DJ (1990). Microgeographic genetic variation in the haploid and diploid stages of the moss Polytrichum juniperinum Hedw. Heredity 64: 331-340.

Kaj I, Krone SM, Lascoux M (2001). Coalescent theory for seed bank models. J Appl Probab 38: 285-300.

Kawecki TJ, Holt RD (2002). Evolutionary consequences of asymmetric dispersal rates. Am Nat 160: 333-347.

Lewis PO, Zaykin D (2001). Genetic Data Analysis: a computer program for the analysis of allelic data. (version 1.0) Free program distributed by the authors. http://lewis.eeb.uconn. edu/lewishome/software.html.

Luo H, Mörchen M, Engel C, Destombe C, Epplen JT, Epplen C et al (1999). Characterisation of microsatellite markers in the red alga, Gracilaria gracilis. Mol Ecol 8: 700-702.

Nei M (1978). Molecular Evolutionary Genetics, Columbia University Press: New York.

Otto SP, Goldstein DB (1992). Recombination and the evolution of diploidy. Genetics 131: 745-751.

Otto SP, Marks JC (1996). Mating systems and the evolutionary transition between haploidy and diploidy. Biol J Linn Soc 57: 197-218.

Palumbi SR (1994). Genetic divergence, reproductive isolation, and marine speciation. Ann Rev Ecol Syst 25: 547-572.

Pamilo P (1993). Polyandry and allele frequency differences between the sexes in the ant Formica aquilonia. Heredity 70: 472-480.

Parker JD, Hedrick PW (2000). Gene flow and selection balance in haplodiploid social insects. Heredity 85: 530-538.

Rannala B, Mountain JL (1997). Detecting immigration by using multilocus genotypes. Proc Natl Acad Sci USA 94: 9197-9201.

Raymond M, Rousset F (1995). GENEPOP (Version 1.2): population genetics software for exact tests and ecumenicism. J Hered 86: 248-249.

Richards AJ (1997). Plant Breeding Systems, Chapman \& Hall: London.

Richerd S (1993). Evolution de l'alternance de phases haploïde et diploïde dans les cycles de reproduction: aspects théoriques et expérimentaux chez l'algue rouge Gracilaria verrucosa. Ph.D. Thesis, de l'Université de Paris 6.

Richerd S, Couvet D, Valero M (1993a). Evolution of alternation of haploid and diploid phases in life cycles. II. Maintenance of the haplo-diplontic cycle. J Evol Biol 6: 263-280.

Richerd S, Destombe C, Cuguen J, Valero M (1993b). Variation of reproductive success in a haplo-diploid red alga, Gracilaria verrucosa: effects of parental identities and crossing distance. Am J Bot 80: 1379-1391.

Rogers DL, Millar CI, Westfall RD (1999). Fine-scale genetic structure of whitebark pine (Pinus albicaulis): association with watershed and growth form. Evolution 53: 74-90.
Rousset F (1999). Genetic differentiation within and between two habitats. Genetics 151: 397-407.

Ruckelshaus MH (1998). Spatial scale of genetic structure and an indirect estimate of gene flow in eelgrass, Zostera marina. Evolution 52: 330-343.

Santelices B (1990). Patterns of reproduction, dispersal and recruitment in seaweeds. Oceanogr Mar Biol 28: 177-276.

Santelices B, Correa J, Aedo D, Flores V, Hormazábal M, Sánchez P (1999). Convergent biological processes in coalescing Rhodophyta. J Phycol 35: 1127-1149.

Schneider S, Roessli D, Excoffier L (2000). Arlequin Ver 2.000: A Software for Population Genetics Data Analysis, Genetics and Biometry Laboratory, University of Geneva: Switzerland.

Shaw AJ (1991). The genetic structure of sporophytic and gametophytic populations of the moss, Funaria hygrometrica Hedw. Evolution 45: 1260-1274.

Slatkin M (1993). Isolation by distance in equilibrium and nonequilibrium populations. Evolution 47: 264-279.

Soltis PS, Soltis DE, Holsinger KE (1988). Estimates of intragametophytic selfing and interpopulational gene flow in homosporous ferns. Am J Bot 75: 1765-1770.

Sork VL, Nason J, Campbell DR, Fernandez JF (1999). Landscape approaches to historical and contemporary gene flow in plants. Trends Ecol Evol 14: 219-223.

Sosa P, Valero M, Batista F, Gonzalez-Pérez MA (1998). Genetic structure of natural populations of Gelidium species: a reevaluation of results. J Appl Phycol 10: 279-284.

Stanton ML, Galen C, Shore J (1997). Population structure along a steep environmental gradient: consequences of flowering time and habitat variation in the snow buttercup, Ranunculus adoneus. Evolution 51: 79-94.

Statsoft Inc. S. (1995). STASTISTICA for windows, Release 5.0. Statsoft Inc.: Tulsa, OK, USA.

Taylor EB, Beacham TD, Kaeriyama M (1994). Population structure and identification of North Pacific Ocean chum salmon (Oncorhynchus keta) revealed by an analysis of minisatellite DNA variation. Can J Fish Aquat Sci 51: 1430-1442.

van der Strate $\mathrm{HJ}$, van de Zande L, Stam WT, Olsen JL (2002). The contribution of haploids, diploids and clones to fine-scale population structure in the seaweed Cladophoropsis membranacea (Chlorophyta). Mol Ecol 11: 329-345.

Waser PM, Strobeck C (1998). Genetic signatures of interpopulation dispersal. Trends Ecol Evol 13: 43-44.

Wattier R, Dallas JF, Destombe C, Saumitou-Laprade P, Valero M (1997). Single locus microsatellites in Gracilariales (Rhodophyta): high level of genetic variability within Gracilaria gracilis and conservation in related species. J Phycol 33: $868-880$

Weir BS (1996). Genetic Data Analysis II: Methods for Discrete Population Genetic Data, Sinauer Associates, Inc.: Sunderland, MA.

Weir BS, Cockerham CC (1984). Estimating F-statistics for the analysis of population structure. Evolution 38: 1358-1370.

Workman PL, Niswander JD (1970). Population studies on southwestern Indian tribes. II. Local genetic differentiation in the Papago. Am J Hum Genet 22: 24-49.

Zuccarello G (2001). Population structure and physiological differentiation of haplotypes of Caloglossa leprieurii (Rhodophyta) in a mangrove intertidal zone. J Phycol 37: 235-244. 